\title{
Preparation of Titanium Dioxide Nanoparticles Immobilized on Polyacrylonitrile Nanofibres for the Photodegradation of Methyl Orange
}

\author{
Pardon Nyamukamba, ${ }^{1}$ Omobola Okoh, ${ }^{1}$ Lilian Tichagwa, ${ }^{2}$ and Corinne Greyling ${ }^{3}$ \\ ${ }^{1}$ Chemistry Department, University of Fort Hare, Private Bag X1314, Alice, South Africa \\ ${ }^{2}$ Department of Polymer Technology and Engineering, Harare Institute of Technology, Belvedere, Zimbabwe \\ ${ }^{3}$ Cape Peninsula University of Technology, Technology Station in Clothing and Textiles, Symphony Way, Bellville, South Africa \\ Correspondence should be addressed to Pardon Nyamukamba; pnyamukamba@ufh.ac.za
}

Received 26 September 2016; Accepted 17 November 2016

Academic Editor: Leonardo Palmisano

Copyright ( 2016 Pardon Nyamukamba et al. This is an open access article distributed under the Creative Commons Attribution License, which permits unrestricted use, distribution, and reproduction in any medium, provided the original work is properly cited.

\begin{abstract}
Herein, we describe the synthesis of titanium dioxide $\left(\mathrm{TiO}_{2}\right)$ nanoparticles by the hydrolysis and condensation of titanium tetrachloride. The resulting nanoparticles were immobilized on polyacrylonitrile (PAN) based nanofibres by an electrospinning technique in order to allow simple isolation and reuse of titania semiconductor photocatalyst. The composite nanofibres were heat treated to convert the polymer nanofibres to carbon nanofibres and to convert amorphous $\mathrm{TiO}_{2}$ to crystalline $\mathrm{TiO}_{2}$. X-ray diffraction (XRD) analysis showed that the rutile phase was the major phase and the equatorial peaks of PAN disappeared after heat treatment at $600^{\circ} \mathrm{C}$. Transmission electron microscopy (TEM) and scanning electron microscopy (SEM) analysis confirmed that some $\mathrm{TiO}_{2}$ nanoparticles were encapsulated whereas some were surface residing on the electrospun nanofibres. The $\mathrm{TiO}_{2}$ nanoparticles were found to lower the cyclization temperature of PAN as indicated by differential scanning colorimetry (DSC) and differential thermal analysis (DTA). Photocatalytic studies on the degradation of methyl orange dye under UV light irradiation showed that composite nanofibres were capable of degrading organic contaminants in water. The carbon nanofibres with surface residing titanium dioxide nanoparticles ( $\mathrm{TiO}_{2} / \mathrm{CNF}-\mathrm{SR}$ ) showed the highest photocatalytic activity ( $59.35 \%$ after 210 minutes) due to direct contact between the $\mathrm{TiO}_{2}$ photocatalyst and methyl orange.
\end{abstract}

\section{Introduction}

The pollution of water by dangerous industrial organic chemicals is a serious problem as it poses a health risk to humans and the environment. These organic contaminants need to be removed if the water is to be used in homes for human consumption. If these organics are not removed, they will react with chlorine during water treatment by chlorination forming by-products such as trihalomethanes, which increase the risk of cancer [1]. Conventional water treatment methods such as adsorption have a disadvantage of producing secondary pollutants that require disposal since it involves accumulation of pollutants on the surface. These disadvantages have prompted research interest into the development of new water treatment methods such as photocatalysis which makes use of a semiconductor photocatalyst that can oxidize organic compounds to harmless products such as water and carbon dioxide [2]. Photocatalysis started in 1972 when Fujishima and Honda discovered the photocatalytic splitting of water using titanium electrodes [3]. The interest in using $\mathrm{TiO}_{2}$ as a heterogeneous catalyst for wastewater and ground water remediation has increased tremendously $[4,5]$ because it is capable of degrading several organic and inorganic pollutants [6].

$\mathrm{TiO}_{2}$ photocatalyst is ideal because it is photostable, relatively cheap, readily available, nontoxic and its photogenerated holes and electrons are highly oxidizing and reducing, respectively [7]. Several methods have been used for the 
synthesis of titania and these include gas phase pyrolysis [8], low temperature dissolution-reprecipitation process [9], solgel [10, 11], combustion synthesis [12], and ultrasonic spray pyrolysis [13]. In this study $\mathrm{TiO}_{2}$ photocatalyst was prepared using a simple sol-gel process.

From a practical point of view, the use of a suspension of powdered $\mathrm{TiO}_{2}$ is very difficult due to filtration problems associated with the small size of the particles. Therefore, for easy isolation and reuse of the photocatalyst in water treatment, $\mathrm{TiO}_{2}$ has been immobilized on solid supports such as silica gel [2], polyester fabric [14], rigid substrates like glass, quartz, and stainless steel [15]. Methods such as electrophoretic deposition [15], dip-coating $[9,15]$, and electrospinning $[16,17]$ have been used to immobilize the $\mathrm{TiO}_{2}$ photocatalyst on supports. It was discovered that the photocatalytic activity of the supported $\mathrm{TiO}_{2}$ was influenced by the adsorption ability of supports to the pollutants, as the pollutants are concentrated around the photocatalyst [18]. In this study, the electrospinning technique was used to immobilize $\mathrm{TiO}_{2}$ photocatalyst on PAN based carbon nanofibres. It was found in other studies to be a unique and cost effective way of making high surface area nanofibres [19].

Electrospinning involves the use of a high voltage, which causes electrostatic charging of the droplet of the polymer, drawing a jet towards the grounded collector [20] to produce an interconnected membrane like a web of small nanofibres. In a typical process, a high voltage is applied between polymer solution droplet at the tip of the capillary tube and a grounded collector. A charged jet of the polymer solution is ejected when the applied electric field overcomes the surface tension of the polymer droplet. The jet then travels to the grounded collector through spiralling loops. To convert the polymer nanofibres to carbon nanofibres, a stabilization process is vital in an oxygen environment to form a thermally stable structure, which can withstand high carbonization temperatures.

\section{Materials and Methods}

2.1. Preparation of $\mathrm{TiO}_{2}$ Embedded Carbon Nanofibres. About $37.54 \mathrm{~mL}$ of absolute ethanol was added dropwise to $12.46 \mathrm{~mL}$ of ice cold titanium tetrachloride solution in conical flask with vigorous stirring to form titanium ethoxide. An appropriate amount of ice cold ethanol/water mixture was then added to the titanium ethoxide dropwise with stirring to give a final concentration of $\mathrm{Ti}^{+4} 0.322 \mathrm{M}$. A few drops of glacial acetic acid were added to control the rate of hydrolysis. The solution was stirred for 2 hours with heating at $60^{\circ} \mathrm{C}$ until the solution turned white and turbid. After the gelation process, about $2 \mathrm{~g}$ of PAN powder was added followed by centrifugation and washing with water and absolute ethanol. Washing with ethanol helped to prevent agglomeration between the precipitates [21]. The PAN/Ti $(\mathrm{OH})_{4}$ complex was then airdried and then dissolved in a suitable amount of DMF to give a 10\% PAN solution followed by electrospinning. Electrospinning was done using a high voltage power supply and a glass pipette of diameter $0.5 \mathrm{~mm}$ inclined at $45^{\circ}$ to minimize dripping of the PAN solution. A voltage of $20 \mathrm{kV}$ was used and the distance between the grounded aluminium foil collectors was $20 \mathrm{~cm}$. After electrospinning, the $\mathrm{PAN} / \mathrm{TiO}_{2}$ composite was stabilized by heating at a rate of $1^{\circ} \mathrm{C}$ per minute up to $280^{\circ} \mathrm{C}$ in an oxygen environment and maintained at that temperature for 2 hours to stabilize the PAN nanofibres and also to remove adsorbed water and solvent. This was then followed by heating at a rate of $5^{\circ} \mathrm{C}$ per minute up to $600^{\circ} \mathrm{C}$ in a nitrogen environment to bring about carbonization of the polymer fibres and calcination of $\mathrm{TiO}_{2}$ particles. The flow rate of the nitrogen gas was $58.6 \mathrm{~mL} / \mathrm{min}$.

2.2. Preparation of Surface Residing $\mathrm{TiO}_{2}$ Carbon Nanofibres. About $0.5 \mathrm{~mL}$ of titanium tetrachloride was added to $18.96 \mathrm{~mL}$ of dimethyl formamide dropwise with vigorous stirring in ice bath. About $2 \mathrm{~g}$ of PAN was then added and stirred until a homogenous PAN solution was formed. The solution was electrospun using a voltage of $20 \mathrm{kV}$ and the distance between the tip of pipette containing the PAN solution and the collector was $20 \mathrm{~cm}$. After electrospinning, the resulting PAN nanofibres containing the $\mathrm{TiO}_{2}$ precursor were immersed in distilled water to bring about the hydrolysis of the titanium tetrachloride. The $\mathrm{PAN} / \mathrm{TiO}_{2}$ nanofibre mats were air-dried at room temperature followed by stabilization and carbonization as reported in Section 2.1.

2.3. Characterization. XRD patterns were obtained using a Bruker AXS (Germany) instrument with a D8 Advance Diffractometer. The $\mathrm{X}$-ray tube used a $\mathrm{Cu}-\mathrm{K}_{\alpha}$ radiation $(\lambda=1.5406 \AA)$ and a gas positron sensitive detector, PSD Vantec-1, with 1600 channels. FTIR spectroscopy was used to determine the functional groups and nature of hydroxyl groups and examine the chemical structures of the polymer to identify the mechanism of the modification reaction during the heat treatment process. The nanofibres were cut into small pieces, mixed with potassium bromide, and then pressed into a disk for the FTIR analysis. The surface morphology of the composite nanofibres was obtained using a JOEL JSM-6390LV Scanning Electron Microscope fitted with a secondary electron detector.

DSC analysis was performed at a heating rate of $10^{\circ} \mathrm{C} /$ minute in nitrogen atmosphere with sample weights of about $5 \mathrm{mg}$ on a Perkin Elmer DSC 7 differential scanning calorimeter equipped with Pyris Software. The thermal stability analysis was done using thermogravimetric instrument supplied by MET-UED, South Africa. About $10 \mathrm{mg}$ of the nanofibres was used for TGA analysis using a heating rate of $10^{\circ} \mathrm{C} /$ minute up to $900^{\circ} \mathrm{C}$ in a nitrogen environment. The change in concentration of the methyl orange during photocatalytic activity evaluation was determined using a Perkin Elmer Lambda 35 UV-Vis spectrophotometer.

2.4. Evaluation of Photocatalytic Activity. The photocatalytic activities of $\mathrm{PAN} / \mathrm{TiO}_{2}-\mathrm{EM}, \mathrm{CNF} / \mathrm{TiO}_{2}-\mathrm{EM}$, and $\mathrm{CNF} / \mathrm{TiO}{ }_{2}-$ SR were investigated using $100 \mathrm{~mL}$ of $10 \mathrm{ppm}$ methyl orange solution at a temperature of $25^{\circ} \mathrm{C}$ and $\mathrm{pH} 7$ in a cylindrical glass vessel. About $1 \mathrm{~g}$ of the composite $\mathrm{TiO}_{2} /$ nanofibres was immersed in methyl orange solution and put in the dark for an hour to allow adsorption and desorption equilibrium to take place. The solution was then irradiated with ultraviolet light of wavelength $365 \mathrm{~nm}$ using a $40 \mathrm{~W}, 220 \mathrm{~V}(50 / 60 \mathrm{~Hz})$ 


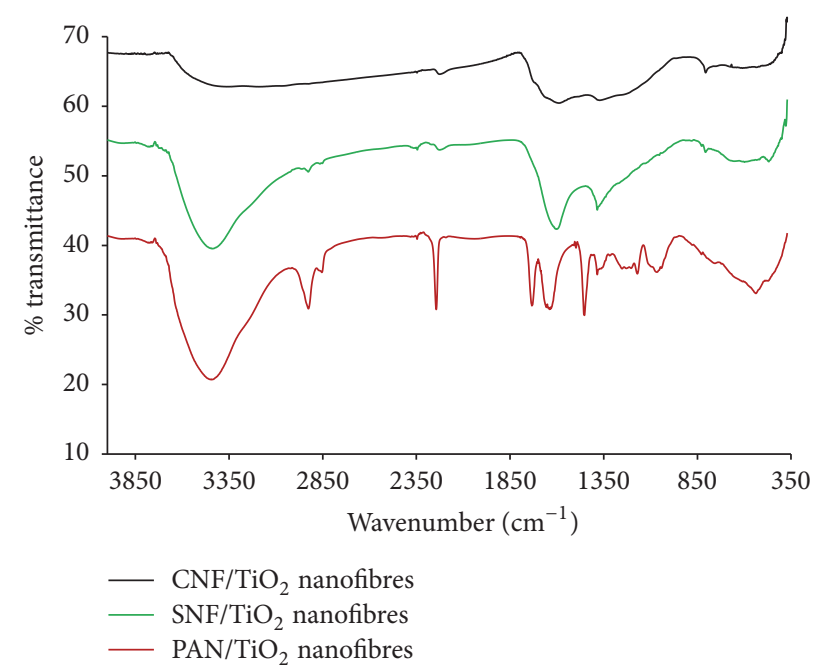

FIGURE 1: FTIR spectra of unstabilized $\mathrm{PAN} / \mathrm{TiO}_{2}, \mathrm{SNF} / \mathrm{TiO}_{2}$, and $\mathrm{CNF} / \mathrm{TiO}_{2}$ composite nanofibres.

lamp fixed at $20 \mathrm{~cm}$ above the solution. After every thirty minutes, aliquots of methyl orange were taken and the concentration was determined using a UV-Vis spectrometer.

2.5. Total Organic Content Measurement. During the photodegradation process, aliquots were taken after every 30 minutes for total organic content (TOC) analysis. This was done using the TOC Fusion which employs the $\mathrm{UV} /$ persulfate oxidation of organic matter into carbon dioxide which is then measured by an NDIR detector which uses the ratio $1: 1$ of carbon dioxide to organic matter in the solution. The other parameters used were as follows: sample volume $4.0 \mathrm{~mL}$, dilution $1: 2$, acid volume $1.0 \mathrm{~mL}$, reagent volume $1.0 \mathrm{~mL}$, UV reactor prerinse volume $5.0 \mathrm{~mL}$, ICS sparge time $1 \mathrm{~min}$, and detector sweep flow $500 \mathrm{~mL} / \mathrm{min}$ and the system flow was $200 \mathrm{~mL} / \mathrm{min}$.

\section{Results and Discussion}

3.1. Fourier Transform Infrared (FTIR) Analysis. Figure 1 shows the FTIR spectra of unstabilized $\mathrm{PAN} / \mathrm{TiO}_{2}$, stabilized $\mathrm{PAN} / \mathrm{TiO}_{2}$, and $\mathrm{CNF} / \mathrm{TiO}_{2}$ composite nanofibres. The spectrum of the stabilized nanofibres clearly shows that the band at $2243 \mathrm{~cm}^{-1}$ which is assigned to $-\mathrm{C} \equiv \mathrm{N}$ stretching decreased considerably (almost disappeared) compared to the same peak in the spectrum of the unstabilized $\mathrm{PAN} / \mathrm{TiO}_{2}$ composite nanofibres. A new peak appeared at $1604 \mathrm{~cm}^{-1}$ in the spectrum of stabilized nanofibres indicating that $\mathrm{C}=\mathrm{C}-$ (aromatic) bonds were formed during the stabilization process. The peaks around $2941 \mathrm{~cm}^{-1}$ and $2892 \mathrm{~cm}^{-1}$ due to asymmetric and symmetric bending in $\mathrm{CH}, \mathrm{CH}_{2}$, and $\mathrm{CH}_{3}$ groups and around $1457 \mathrm{~cm}^{-1}$ due to $\mathrm{CH}$ bending [22] reduced in intensity significantly in the spectrum of $\mathrm{SNF} / \mathrm{TiO}_{2}$ when compared to the spectrum of unstabilized nanofibres. This indicates that cyclization and dehydrogenation reaction occurred during thermal oxidative stabilization of PAN nanofibres resulting in the formation of an aromatic heat-resistant structure. These peaks completely disappeared in the spectrum of $\mathrm{CNF} / \mathrm{TiO}_{2}$ showing that almost all the hydrogen had been lost during the carbonization process. Some researchers $[23,24]$ reported that the peak around $1630 \mathrm{~cm}^{-1}$ indicates the presence of $-\mathrm{C}=\mathrm{C}-$ bond and in this study this peak appeared in the spectrum of $\mathrm{SNF} / \mathrm{TiO}_{2}$ and $\mathrm{CNF} / \mathrm{TiO}_{2}$ but not in the spectrum of the unstabilized PAN nanofibres. The peak around $3457 \mathrm{~cm}^{-1}$ was due to $\mathrm{OH}$ group. Exposure of $\mathrm{TiO}_{2}$ to moisture causes hydroxylation of the surface by chemisorption of water molecules. The peak around $500 \mathrm{~cm}^{-1}$ corresponds to $\mathrm{Ti}-\mathrm{O}$ and $\mathrm{Ti}-\mathrm{O}-\mathrm{Ti}$ bands [25]. The peaks at $1171 \mathrm{~cm}^{-1}$ (medium) and $1739 \mathrm{~cm}^{-1}$ (very sharp) were due to $\mathrm{C}=\mathrm{O}$ of the residual DMF and these peaks disappeared in the spectrum of the stabilized nanofibres due to loss of the solvent.

3.2. Scanning Electron Microscope Analysis. Figure 2 shows the SEM images of neat PAN nanofibres, neat carbon nanofibres, $\mathrm{TiO}_{2}$ embedded PAN nanofibres (PAN/TiO $\left.-\mathrm{EM}\right)$, and $\mathrm{TiO}_{2}$ surface residing carbon nanofibres $\left(\mathrm{CNF} / \mathrm{TiO}{ }_{2}-\mathrm{SR}\right)$. The surfaces of neat PAN nanofibres (Figure 2(a)) were smooth but the surfaces of the composites, $\mathrm{PAN} / \mathrm{TiO}_{2}-\mathrm{EM}$ nanofibres (Figure 2(c)) and $\mathrm{CNF} / \mathrm{TiO}_{2}-\mathrm{SR}$ (Figure 2(d)) nanofibres, were rough due to the encapsulated and surface residing $\mathrm{TiO}_{2}$ nanoparticles, respectively. All the heat treated nanofibres were much darker in colour when compared to the PAN nanofibres which were not heat treated. The colour changes that were observed during the heat treatment were from white to brown after stabilization and black after carbonization. The $\mathrm{TiO}_{2}$ particles of the $\mathrm{PAN} / \mathrm{TiO}_{2}-\mathrm{EM}$ nanofibres were dispersed fairly uniformly over the carbon nanofibres because the $\mathrm{TiO}_{2}$ nanoparticles were dispersed homogenously in the PAN solution before electrospinning. It was difficult to find the size of the $\mathrm{TiO}_{2}$ in $\mathrm{PAN} / \mathrm{TiO}_{2}$-EM because the nanoparticles were encapsulated showing that the nanoparticles were far less than the diameter of the nanofibres ca. 150 to $200 \mathrm{~nm}$.

The EDS graph of the $\mathrm{CNF} / \mathrm{TiO}_{2}$ composite nanofibres is shown in Figure 3 and it showed the presence of carbon, titanium, and oxygen as expected. The peak around $0.4,4.5$, and $5 \mathrm{keV}$ corresponds to titanium.

3.3. Thermal Properties. Thermogravimetric (TGA) and differential scanning calorimetry (DSC) analyses were done to get information about the changes that occur to PAN and $\mathrm{TiO}_{2}$ during calcination and stabilization processes. In order to obtain high performance commercial PAN based carbon fibres, it is vital to stabilize the nanofibres completely. Figure 4 shows the DSC of unstabilized neat PAN and stabilized neat $\mathrm{PAN}$ and $\mathrm{PAN} / \mathrm{TiO}_{2}$ nanofibres. The onset temperature of the cyclization of PAN, glass transition temperature $\left(T_{\mathrm{g}}\right)$ of PAN, conversion of the remaining $\mathrm{Ti}(\mathrm{OH})_{4}$ to $\mathrm{TiO}_{2}$, and crystallization of $\mathrm{TiO}_{2}$ could be easily determined from the DSC thermogram.

There were minor discontinuities at the start of the thermograms which do not seem to be thermal events. These discontinuities are an undesired alteration in data related to the start of the DSC heating program [26]. In the thermogram of $\mathrm{PAN} / \mathrm{TiO}_{2}$ nanofibres, an endothermic peak between $30^{\circ} \mathrm{C}$ 


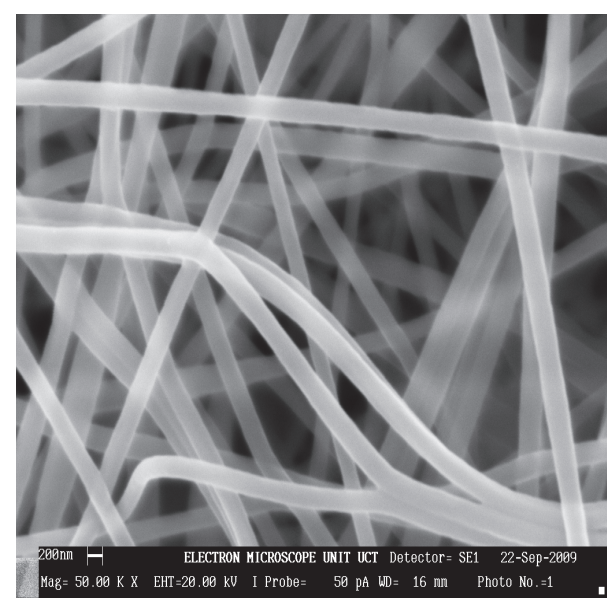

(a)

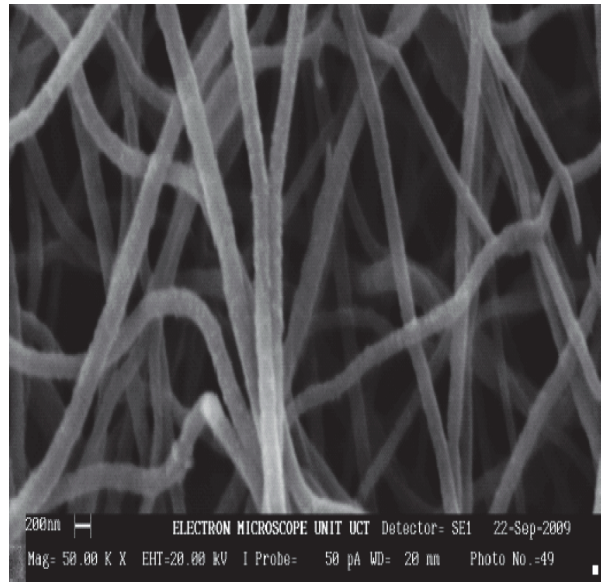

(c)

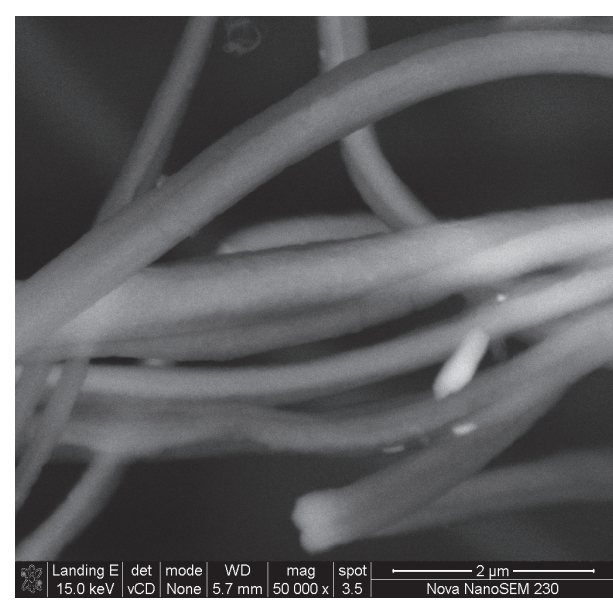

(b)

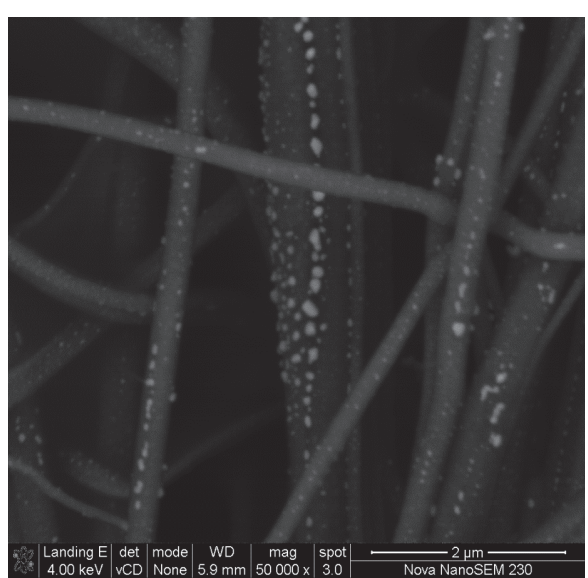

(d)

FIgURE 2: SEM images of (a) neat PAN nanofibres, (b) neat carbon nanofibres, (c) $\mathrm{PAN}_{\mathrm{TiO}}$-EM, and (d) $\mathrm{CNF} / \mathrm{TiO}{ }_{2}-\mathrm{SR}$ nanofibres. The magnification was 50000 .

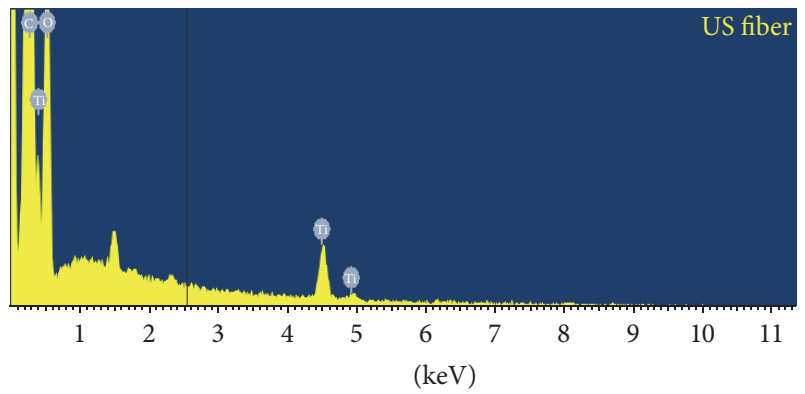

Full scale 1143 cts cursor: 2.547 ( 85 cts)

Figure 3: EDX spectrum of $\mathrm{CNF} / \mathrm{TiO}_{2}$.

and $150^{\circ} \mathrm{C}$ was due to the conversion (thermal decomposition) of the remaining $\mathrm{Ti}(\mathrm{OH})_{4}$ to $\mathrm{TiO}_{2}$, volatilization of some organic materials, and evaporation/desorption of physically adsorbed water and solvent $[27,28]$. The exothermic peak between $310^{\circ} \mathrm{C}$ and $325^{\circ} \mathrm{C}$ was common to thermograms

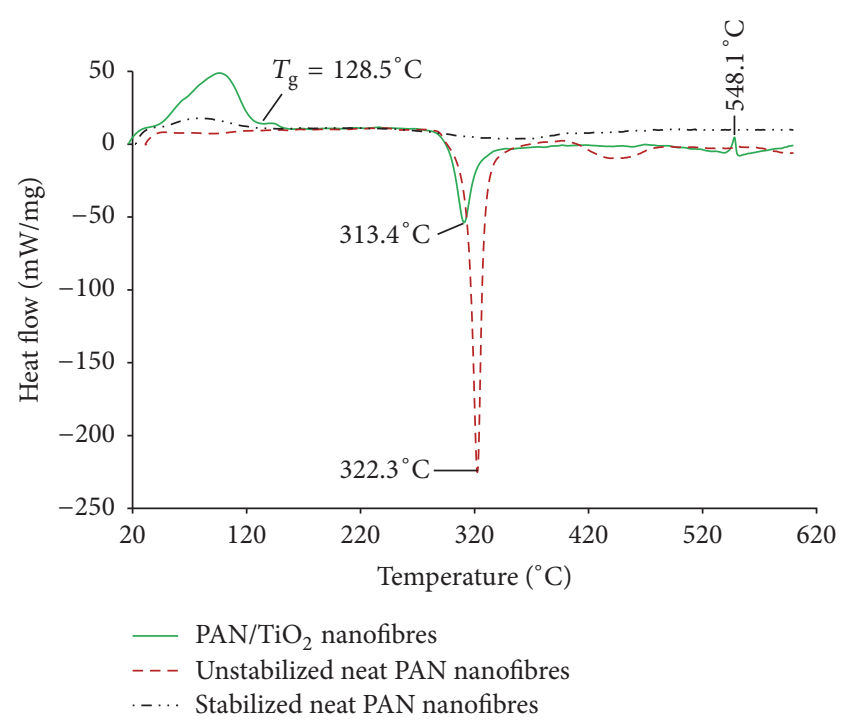

FIGURE 4: DSC curves of neat PAN and stabilized neat PAN and $\mathrm{PAN} / \mathrm{TiO}_{2}$ nanofibres. 


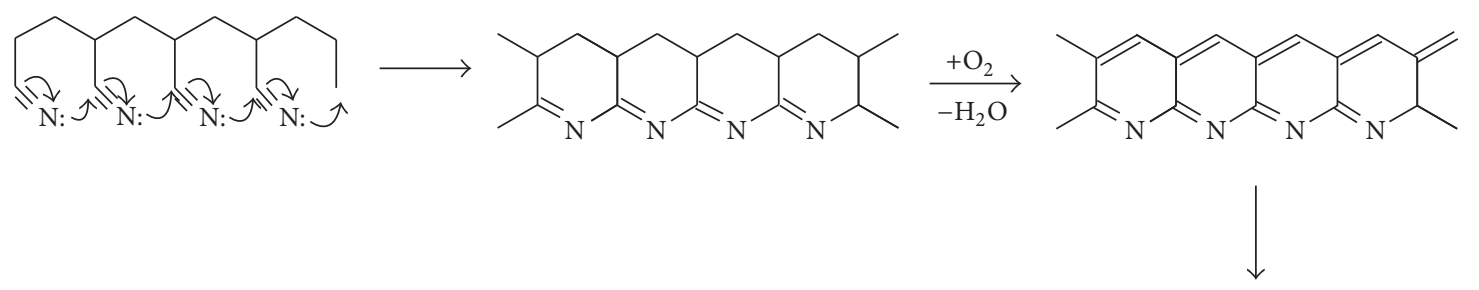

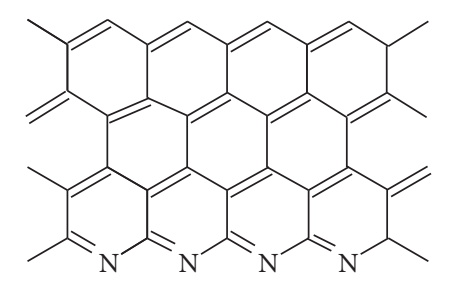
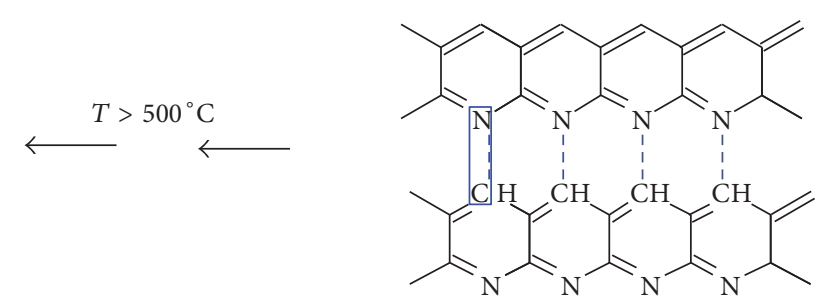

FIGURE 5: Stages of the conversion of polymeric PAN to carbon nanofibres.

of both $\mathrm{PAN} / \mathrm{TiO}_{2}$ nanofibres and unstabilized neat PAN nanofibres and can be attributed to the crosslinking and cyclization of the nitrile groups of PAN. The cyclisation reactions are extremely exothermic [29].

The exothermic peak for the neat PAN was sharp and intense and it appeared at a higher temperature $\left(\mathrm{ca} .322 .3^{\circ} \mathrm{C}\right)$ compared to that of the composite nanofibres which was small and appeared at a lower temperature $\left(\mathrm{ca} .313 .4^{\circ} \mathrm{C}\right)$. The reason for the appearance of the exothermic peak of the composite nanofibres at a lower temperature than neat PAN could probably be the presence of titanium dioxide, which could have affected the exothermic reaction by initiating the stabilization reactions and facilitating the process. The endothermic peak at $548.1^{\circ} \mathrm{C}$ was due to amorphous to crystalline anatase phase transformation of $\mathrm{TiO}_{2}$ [30]. The presence of titanium in the PAN helped in the determination of the glass transition temperature easily as this was insignificant in the DSC curve of neat PAN. The literature value of the glass transition temperature $\left(T_{\mathrm{g}}\right)$ of pure PAN is $125^{\circ} \mathrm{C}$ and in this study as can be seen in the DSC curve of PAN containing titanium tetrahydroxide was $128.5^{\circ} \mathrm{C}$ which showed an increment of $3.5^{\circ} \mathrm{C}$. This increment is probably due to the additive, titanium dioxide nanoparticles. The DSC curve for the stabilized PAN nanofibres was almost a straight line with no exothermic peaks showing that stabilization was basically complete and a heat-resistant ladder structure had formed; therefore in this work cyclization was complete at $280^{\circ} \mathrm{C}$.

The proposed stages in the conversion of PAN to carbon nanofibres are shown in Figure 5. The reactions involved in the conversion are very complex but include the cyclization of the nitrile groups and crosslinking of the PAN straight chains forming a ladder polymer, which cannot melt during the carbonization process. Carbonization involves the removal of noncarbon elements in form of gases such as $\mathrm{NH}_{3}, \mathrm{CO}_{2}, \mathrm{~N}$, $\mathrm{CO}$, and water vapour [31].

Figure 6 shows the TGA thermogram and DTA curves of polyacrylonitrile containing $\mathrm{TiO}_{2}$ using a heating rate of $10^{\circ} \mathrm{C} /$ minute in the temperature range of $25-900^{\circ} \mathrm{C}$. A small

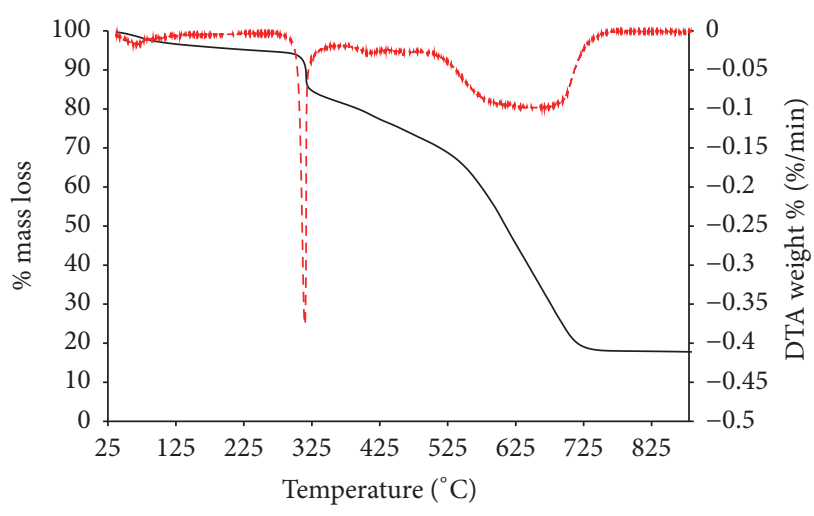

FIGURE 6: TGA thermograms of $\mathrm{PAN} / \mathrm{TiO}_{2}$ nanofibres.

weight loss of about $2.5 \%$ between $20^{\circ} \mathrm{C}$ and $100^{\circ} \mathrm{C}$ was due to the release of adsorbed water and solvents. Around $313.9^{\circ} \mathrm{C}$ the weight loss of $7 \%$ of the composite nanofibres was due to cyclization of the PAN, which is in agreement with the DSC analysis.

3.4. Raman Analysis. Raman spectroscopy is a nondestructive, quick, and noncontacting technique that is commonly used to characterize and study the microstructural and phase information of carbon related materials. Figure 7 shows the Raman spectra of the $\mathrm{CNF} / \mathrm{TiO}_{2}$ and unstabilized and stabilized composite nanofibres using a laser with an excitation wavelength of $514.5 \mathrm{~nm}$ in the range of Raman shift of 949 to $2900 \mathrm{~cm}^{-1}$. Normally carbon fibres show two peaks, the $D$ and $G$ peaks around $1360 \mathrm{~cm}^{-1}$ and $1580 \mathrm{~cm}^{-1}$, respectively $[32,33]$. In this study, the $D$ peak of the $\mathrm{CNF} / \mathrm{TiO}_{2}$ was found at $1362 \mathrm{~cm}^{-1}$ and the $\mathrm{G}$ peak appeared at $1564 \mathrm{~cm}^{-1}$. The presence of the $\mathrm{G}$ peak in the spectrum of $\mathrm{CNF} / \mathrm{TiO}_{2}$ indicated the presence of Raman active $\mathrm{sp}^{2}$ carbon networks. The Raman spectra of the stabilized and unstabilized composite nanofibres did not give clear distinct $\mathrm{D}$ and $\mathrm{G}$ peaks. The unstabilized $\mathrm{PAN} / \mathrm{TiO}_{2}$ composite fibres 


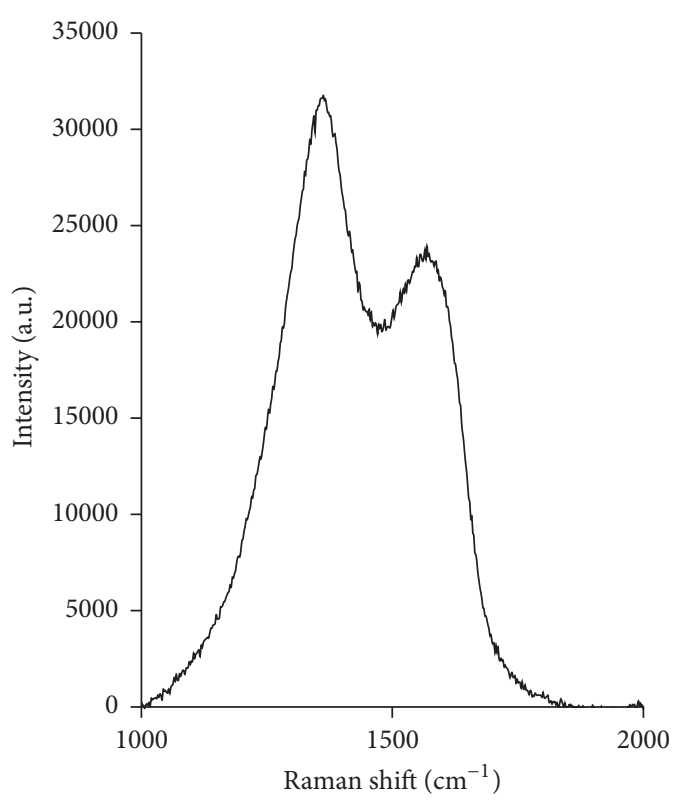

(a)

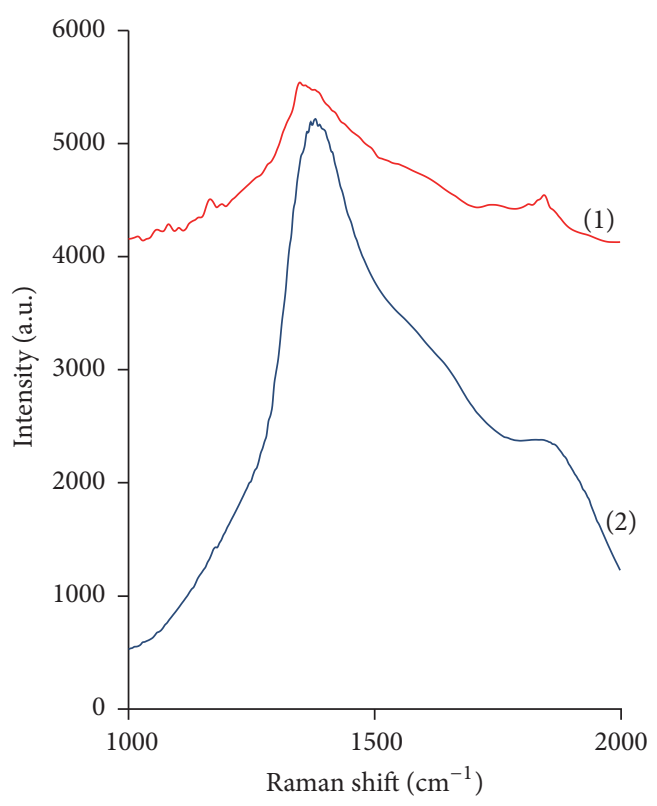

(b)

FIGURE 7: Raman spectrum of (a) $\mathrm{CNF} / \mathrm{TiO}_{2}$, (b1) unstabilized $\mathrm{PAN} / \mathrm{TiO}_{2}$ nanofibres, and (b2) stabilized $\mathrm{PAN} / \mathrm{TiO} \mathrm{O}_{2}$ nanofibres using 514.5 nm laser excitation.

showed a small broad D peak compared to the heat treated fibres (stabilized and $\mathrm{CNF} / \mathrm{TiO}_{2}$ composite nanofibers) and this agrees well with what was reported in literature [33]. The peak around $1865 \mathrm{~cm}^{-1}$ in the spectrum of unstabilized nanofibres was due to the presence of linear carbon chains [34]. As the temperature was increased, the intensity of the peaks increased. From these spectra, it can be observed that the $\mathrm{G}$ band is a feature for the highly ordered graphite structure, which was found in the carbonized nanofibres and this agrees well with what was reported in literature [34]. As the temperature was increased, the disordered carbon structure transformed into a more ordered graphitic carbon structure with good mechanical properties.

Figure 8 shows the XRD patterns of $\mathrm{CNF} / \mathrm{TiO}_{2}$ and neat PAN nanofibres. In the XRD pattern of neat nanofibres, two equatorial peaks at $2 \theta$ values of $17.1^{\circ}$ and $29.1^{\circ}$ were observed. These peaks disappeared upon carbonization and after oxidation as these peaks could not appear in the XRD patterns of the $\mathrm{CNF} / \mathrm{TiO}_{2}$. The peaks at $2 \theta$ values of $27.0^{\circ}$, $36.1^{\circ}, 40.2^{\circ}, 43.5^{\circ}, 54.1^{\circ}$, and $68.6^{\circ}$ indicate the presence of $\mathrm{TiO}_{2}$ in the rutile phase while small peaks at $2 \theta$ values of $25.1^{\circ}$, $47.2^{\circ}$, and $62.3^{\circ}$ correspond to the diffraction of (101), (200), and (204) crystal faces of the anatase phase of $\mathrm{TiO}_{2}$ [35]. The major $\mathrm{TiO}_{2}$ phase was the rutile phase because of the heat treatment up to $600^{\circ} \mathrm{C}$ during the carbonization stage that transformed the anatase to rutile phase.

3.5. Photocatalytic Activity Evaluation. Methyl orange was chosen as a model of the azo dyes that are mainly used in the chemical and textile industries. After an hour in the dark to allow desorption and adsorption equilibrium to take place on the composite nanofibres, it was observed that the absorbance which is proportional to the change in concentration was

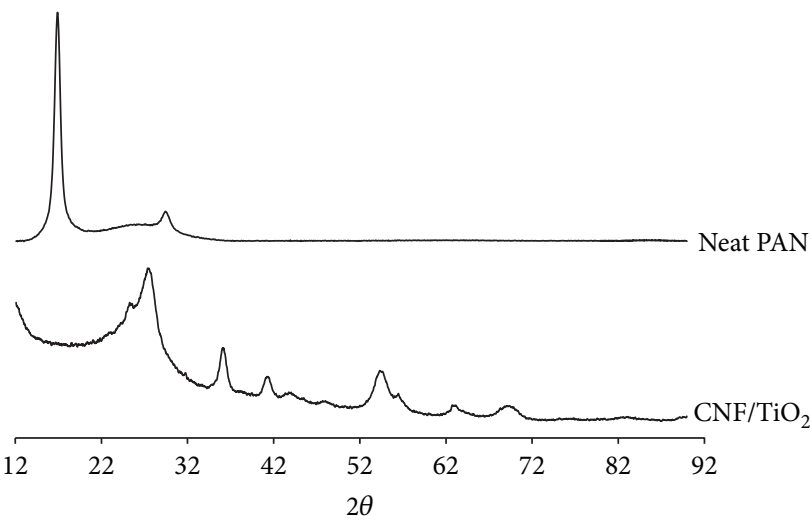

FIGURE 8: XRD patterns of neat PAN nanofibres and $\mathrm{CNF} / \mathrm{TiO}_{2}$.

reduced from 0.512 to 0.489 by $\mathrm{CNF} / \mathrm{TiO}_{2}$, to 0.462 by $\mathrm{SNF} / \mathrm{TiO}_{2}$, and to 0.413 by $\mathrm{PAN} / \mathrm{TiO}_{2}$ as shown in Figure 9 . This showed that the PAN nanofibres were better adsorbents than heat treated polymer nanofibres. This is because PAN is polar and methyl orange is also polar; hence the interaction between the adsorbate and the surface sites of the adsorbent was enhanced.

Figure 10 shows the changes in concentration of methyl orange as a function of time under UV illumination for $\mathrm{CNF} / \mathrm{TiO}_{2}-\mathrm{EM}, \mathrm{CNF} / \mathrm{TiO}_{2}-\mathrm{SR}, \mathrm{SNF} / \mathrm{TiO}_{2}$, and $\mathrm{PAN} / \mathrm{TiO}_{2}$. The $\mathrm{CNF} / \mathrm{TiO}_{2}-\mathrm{SR}$ showed the highest photocatalytic activity and it degraded $59.35 \%$ of methyl orange after 210 minutes followed by $\mathrm{CNF} / \mathrm{TiO}_{2}$-EM, which degraded $25.48 \%$, and $\mathrm{SNF} / \mathrm{TiO}_{2} 21.58 \%$ and $\mathrm{PAN} / \mathrm{TiO}_{2}$ showed the least (16.44\%). The reasons for the general higher photocatalytic activities of $\mathrm{TiO}_{2}$ in the $\mathrm{CNF}$ are that, during the carbonization 


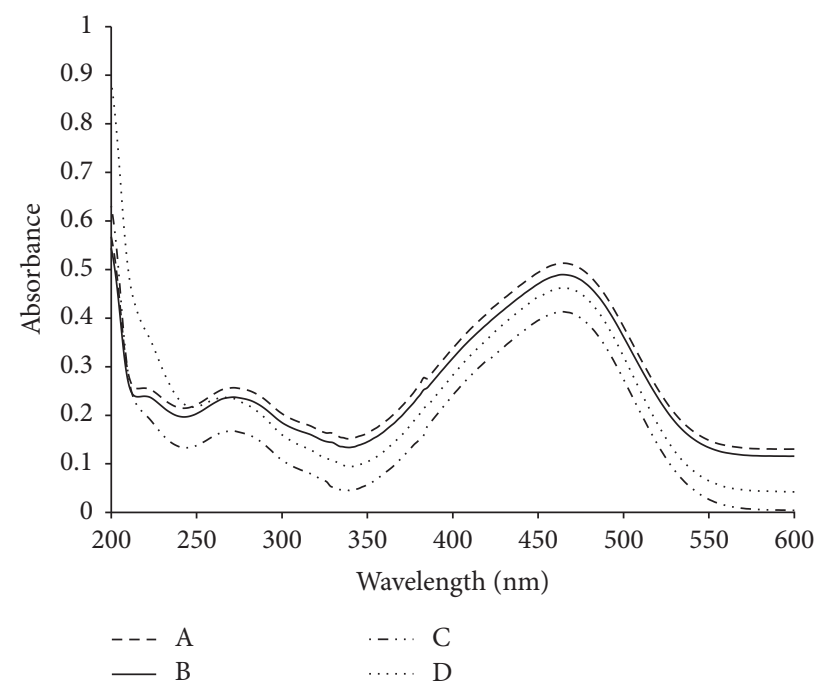

FIGURE 9: Change in absorbance of methyl orange due to adsorption by (A) initial (B) $\mathrm{CNF} / \mathrm{TiO}_{2}$, (C) $\mathrm{PAN} / \mathrm{TiO}_{2}$, and (D) $\mathrm{SNF} / \mathrm{TiO}_{2}$.

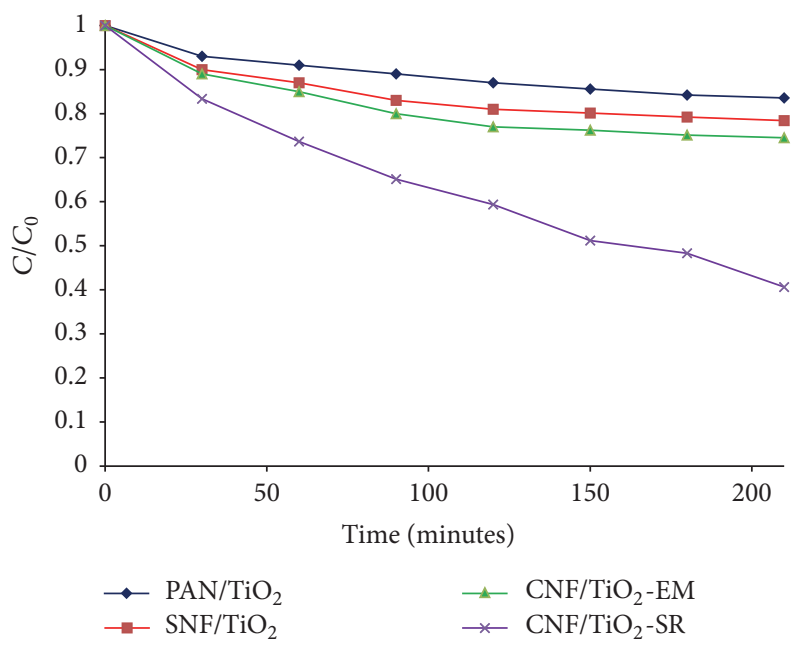

FIGURE 10: Photodegradation curves of methyl orange concentration as a function of time using the composite nanofibres at $25^{\circ} \mathrm{C}$ and $\mathrm{pH}$ 7.

of the polymer nanofibres, calcination of $\mathrm{TiO}_{2}$ occurred resulting in increased crystallinity and anatase to rutile phase transformation. Crystallinity increases the photocatalytic activity of the $\mathrm{TiO}_{2}$ nanoparticles. The anatase to rutile phase transformation that occurred resulted in a mixture of the two phases on the CNF. Although anatase has been reported to be more photocatalytically active than the rutile phase, a mixture of anatase and rutile with a ratio of $75: 25$ was found to be beneficial in reducing recombination of charge carriers resulting in a much higher photocatalytic activity than either pure anatase or pure rutile $\mathrm{TiO}_{2}$ photocatalyst $[36,37]$. This shows that heat treatment is an important step in the preparation of a semiconductor photocatalyst. These results clearly indicate that polymer nanofibres are promising supports for semiconductor photocatalysts as they can adsorb
TABLE 1: TOC analysis results of methyl orange photodegradation.

\begin{tabular}{lc}
\hline Time (minutes) & TOC $(\mathrm{mg} / \mathrm{L})$ \\
\hline 0 & 73.5 \\
30 & 66.3 \\
60 & 61.1 \\
90 & 52.3 \\
150 & 46.3 \\
180 & 44.5 \\
\hline
\end{tabular}

pollutants bringing them closer to the photocatalyst to be degraded.

The difference in the photocatalytic activities of the $\mathrm{CNF} / \mathrm{TiO}_{2}-\mathrm{EM}$ and $\mathrm{CNF} / \mathrm{TiO}_{2}-\mathrm{SR}$ was attributed to the total surface area of $\mathrm{TiO}_{2}$ nanoparticles in contact with methyl orange. In $\mathrm{CNF} / \mathrm{TiO}_{2}-\mathrm{EM}$, some of the nanoparticles were encapsulated meaning they were not in direct contact with the contaminant; hence its photocatalytic activity was lower than that of $\mathrm{CNF} / \mathrm{TiO}_{2}-\mathrm{SR}$.

The stability of the nanofibre supports was checked by SEM analysis before and after the photocatalytic process. It was discovered that there was relatively no changes in nanofibre morphology that occurred indicating that the nanofibres were relatively stable.

Table 1 shows the TOC analysis results of methyl orange photodegradation catalyzed by $\mathrm{CNF} / \mathrm{TiO}_{2}$-SR which was the best photocatalyst. The TOC could be quantified by measuring the carbon dioxide generated when the organic compounds were oxidized and according to Luo and coworkers (2015) it excludes the inorganic carbon compounds [38]. Generally there was a decrease in the TOC with increase in photodegradation time.

\section{Conclusions}

Titanium dioxide nanoparticles immobilized on carbon nanofibres via electrospinning and annealing the $\mathrm{PAN} / \mathrm{TiO}{ }_{2}$ composite were successfully prepared. The neat electrospun nanofibres displayed a very sharp exothermic peak at $322.3^{\circ} \mathrm{C}$ whereas the composite displayed it at $313.4^{\circ} \mathrm{C}$. The titanium dioxide was found to lower the cyclization temperature of the polyacrylonitrile as indicated by DSC and DTA analysis. The $\mathrm{CNF} / \mathrm{TiO}_{2}-\mathrm{SR}$ exhibited a higher photocatalytic activity than $\mathrm{CNF} / \mathrm{TiO}_{2}-\mathrm{EM}, \mathrm{SNF} / \mathrm{TiO}_{2}$, and $\mathrm{PAN} / \mathrm{TiO}_{2}$ nanofibres. Calcination at high temperatures is a way of improving the crystallinity and had a beneficial effect on the photocatalytic activity of $\mathrm{TiO}_{2}$. It was noted that polymer nanofibres have a high adsorption capacity compared to the heat treated polymer nanofibres.

\section{Competing Interests}

The authors declare no conflict of interests.

\section{Acknowledgments}

The authors would like to thank the National Research Foundation and the Department of Science and Technology 
of South Africa for their generous financial support as part of the Nanotechnology for Water Treatment Flagship with Professor Sanderson as the grant holder.

\section{References}

[1] B. I. Dvorak and S. O. Skipton, Drinking Water Treatment, Activated Carbon Filtration, University of Nebraska-Lincoln Extension, vol. 1, Institute of Agriculture and Natural Resources, Lincoln, Neb, USA, 2008.

[2] N. F. Zainudin, A. Z. Abdullah, and A. R. Mohamed, "Characteristics of supported nano- $\mathrm{TiO}_{2} / \mathrm{ZSM}-5 /$ silica gel (SNTZS): photocatalytic degradation of phenol," Journal of Hazardous Materials, vol. 174, no. 1-3, pp. 299-306, 2010.

[3] A. Fujishima and K. Honda, "Electrochemical photolysis of water at a semiconductor electrode," Nature, vol. 238, no. 5358, pp. 37-38, 1972.

[4] M. Kositzi, I. Poulios, S. Malato, J. Caceres, and A. Campos, "Solar photocatalytic treatment of synthetic municipal wastewater," Water Research, vol. 38, no. 5, pp. 1147-1154, 2004.

[5] O. Prieto, J. Fermoso, Y. Nuñez, J. L. Del Valle, and R. Irusta, "Decolouration of textile dyes in wastewaters by photocatalysis with $\mathrm{TiO}_{2}$," Solar Energy, vol. 79, no. 4, pp. 376-383, 2005.

[6] K. Kabra, R. Chaudhary, and R. L. Sawhney, "Treatment of hazardous organic and inorganic compounds through aqueousphase photocatalysis: a review," Industrial and Engineering Chemistry Research, vol. 43, no. 24, pp. 7683-7696, 2004.

[7] M. Hussain, R. Ceccarelli, D. L. Marchisio, D. Fino, N. Russo, and F. Geobaldo, "Synthesis, characterization, and photocatalytic application of novel $\mathrm{TiO}_{2}$ nanoparticles," Chemical Engineering Journal, vol. 157, no. 1, pp. 45-51, 2010.

[8] K. Y. Jung, S. B. Park, and H. D. Jang, "Phase control and photocatalytic properties of nano-sized titania particles by gasphase pyrolysis of $\mathrm{TiCl}_{4}$," Catalysis Communications, vol. 5, no. 9, pp. 491-497, 2004.

[9] Z. Liuxue, L. Peng, and S. Zhixing, "Photocatalysis anatase thin film coated PAN fibers prepared at low temperature," Materials Chemistry and Physics, vol. 98, no. 1, pp. 111-115, 2006.

[10] S. Rengaraj and X. Z. Li, "Enhanced photocatalytic activity of $\mathrm{TiO}_{2}$ by doping with $\mathrm{Ag}$ for degradation of 2,4,6-trichlorophenol in aqueous suspension," Journal of Molecular Catalysis A: Chemical, vol. 243, no. 1, pp. 60-67, 2006.

[11] K. Mogyorósi, I. Dékány, and J. H. Fendler, "Preparation and characterization of clay mineral intercalated titanium dioxide nanoparticles," Langmuir, vol. 19, no. 7, pp. 2938-2946, 2003.

[12] Y. Kitamura, N. Okinaka, T. Shibayama et al., "Combustion synthesis of $\mathrm{TiO}_{2}$ nanoparticles as photocatalyst," Powder Technology, vol. 176, no. 2-3, pp. 93-98, 2007.

[13] L. Castañeda and M. Terrones, "Synthesis and structural characterization of novel flower-like titanium dioxide nanostructures," Physica B: Condensed Matter, vol. 390, no. 1-2, pp. 143-146, 2007.

[14] H. Žabová and B. Dvořák, "Gas phase degradation of acetone using a $\mathrm{TiO}_{2}$ photocatalyst supported on a polyester fabric," Reaction Kinetics and Catalysis Letters, vol. 98, no. 1, pp. 165175, 2009.

[15] A. Fernández, G. Lassaletta, V. M. Jiménez et al., "Preparation and characterization of $\mathrm{TiO}_{2}$ photocatalysts supported on various rigid supports (glass, quartz and stainless steel). Comparative studies of photocatalytic activity in water purification," Applied Catalysis B, Environmental, vol. 7, no. 1-2, pp. 49-63, 1995.
[16] C. Tekmen, A. Suslu, and U. Cocen, "Titania nanofibers prepared by electrospinning," Materials Letters, vol. 62, no. 29, pp. 4470-4472, 2008.

[17] Y. Hong, D. Li, J. Zheng, and G. Zou, "Sol-gel growth of titania from electrospun polyacrylonitrile nanofibres," Nanotechnology, vol. 17, no. 8, pp. 1986-1993, 2006.

[18] H. Song, H. Jiang, X. Liu, and G. Meng, "Nano $\mathrm{TiO}_{2}$ on crude mineral and the photoactivity to the degradation of chloroform," American Journal of Environmental Sciences, vol. 2, pp. 60-65, 2006.

[19] J. Doshi and D. H. Reneker, "Electrospinning process and applications of electrospun fibers," Journal of Electrostatics, vol. 35, no. 2-3, pp. 151-160, 1995.

[20] S. Kedem, J. Schmidt, Y. Paz, and Y. Cohen, "Composite polymer nanofibers with carbon nanotubes and titanium dioxide particles," Langmuir, vol. 21, no. 12, pp. 5600-5604, 2005.

[21] K. R. Lee, S. J. Kim, J. S. Song, J. H. Lee, Y. J. Chung, and S. Park, "Photocatalytic characteristics of nanometer-sized titania powders fabricated by a homogeneous-precipitation process," Journal of the American Ceramic Society, vol. 85, no. 2, pp. 341345, 2002.

[22] S. Deng, R. Bai, and J. P. Chen, "Aminated polyacrylonitrile fibers for lead and copper removal," Langmuir, vol. 19, no. 12, pp. 5058-5064, 2003.

[23] Y. Rong, H.-Z. Chen, G. Wu, and M. Wang, "Preparation and characterization of titanium dioxide nanoparticle/polystyrene composites via radical polymerization," Materials Chemistry and Physics, vol. 91, no. 2-3, pp. 370-374, 2005.

[24] M. Zhu, Q. Xing, H. He et al., "Preparation of PA6/nano titanium dioxide $\left(\mathrm{TiO}_{2}\right)$ composites and their spinnability," Macromolecular Symposia, vol. 210, no. 1, pp. 251-261, 2004.

[25] C. A. Páez, D. Poelman, J.-P. Pirard, and B. Heinrichs, "Unpredictable photocatalytic ability of $\mathrm{H}_{2}$-reduced rutile- $\mathrm{TiO}_{2}$ xerogel in the degradation of dye-pollutants under UV and visible light irradiation," Applied Catalysis B: Environmental, vol. 94, no. 3-4, pp. 263-271, 2010.

[26] M. E. Brown, Introduction to Thermal Analysis Techniques and Applications, 1988.

[27] J. G. Yu, X. Zhao, and Q. Zhao, "Effect of surface structure on photocatalytic activity of $\mathrm{TiO}_{2}$ thin films prepared by sol-gel method," Thin Solid Films, vol. 379, no. 1-2, pp. 7-14, 2000.

[28] T. Wen, J. Gao, J. Shen, and Z. Zhou, "Preparation and characterization of $\mathrm{TiO}_{2}$ thin films by the sol-gel process," Journal of Materials Science, vol. 36, no. 24, pp. 5923-5926, 2001.

[29] M. C. Paiva, P. Kotasthane, D. D. Edie, and A. A. Ogale, "UV stabilization route for melt-processible PAN-based carbon fibers," Carbon, vol. 41, no. 7, pp. 1399-1409, 2003.

[30] J. A. Navio, M. Macias, M. Gonzalez-Catalan, and A. Justo, "Bulk and surface characterization of powder iron-doped titania photocatalysts," Journal of Materials Science, vol. 27, no. 11, pp. 3036-3042, 1992.

[31] A. Sedghi, R. E. Farsani, and A. Shokuhfar, "The effect of commercial polyacrylonitrile fibers characterizations on the produced carbon fibers properties," Journal of Materials Processing Technology, vol. 198, no. 1-3, pp. 60-67, 2008.

[32] F. Liu, H. Wang, L. Xue, L. Fan, and Z. Zhu, "Effect of microstructure on the mechanical properties of PAN-based carbon fibers during high-temperature graphitization," Journal of Materials Science, vol. 43, no. 12, pp. 4316-4322, 2008.

[33] G. Washer and F. Blum, "Raman spectroscopy for the nondestructive testing of carbon fiber," Research Letters in Materials Science, vol. 2008, Article ID 693207, 3 pages, 2008. 
[34] M. A. Pimenta, G. Dresselhaus, M. S. Dresselhaus, L. G. Cançado, A. Jorio, and R. Saito, "Studying disorder in graphitebased systems by Raman spectroscopy," Physical Chemistry Chemical Physics, vol. 9, no. 11, pp. 1276-1290, 2007.

[35] G. An, C. Yang, Y. Zhou, and X. Zhao, "Plasmon-enhanced photoluminescence from $\mathrm{TiO}_{2}: \mathrm{Sm}^{3+}$ :Au nanostructure," Physica Status Solidi (A) Applications and Materials Science, vol. 209, no. 12, pp. 2583-2588, 2012.

[36] G. R. Haizel, "Optical properties and photocatalytic activities of titania nanoflowers synthesized by microwave irradiation," The International Journal of Innovative Research in Science, Engineering and Technology, vol. 2, pp. 2175-2181, 2013.

[37] J. Zhang, Q. Xu, Z. Feng, M. Li, and C. Li, "Importance of the relationship between surface phases and photo-catalytic activity of $\mathrm{TiO}_{2}$," Angewandte Chemie-International Edition, vol. 47, no. 9, pp. 1766-1769, 2008.

[38] Q. Luo, X. Wang, D. Wang, J. An, X. Li, and R. Yin, “ $\mathrm{TiO}_{2} /$ cyclized polyacrylonitrile hybridized nanocomposite: an efficient visible-light photocatalyst prepared by a facile 'in situ' approach," Materials Science and Engineering B, vol. 199, pp. 96104,2015 

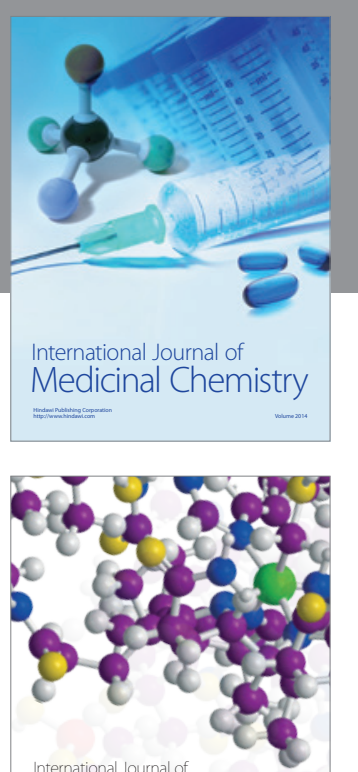

Carbohydrate Chemistry

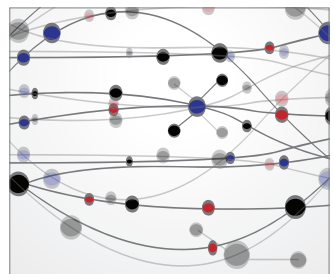

The Scientific World Journal
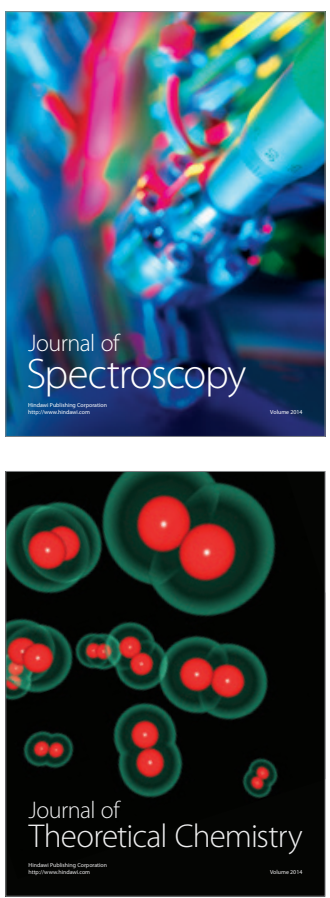
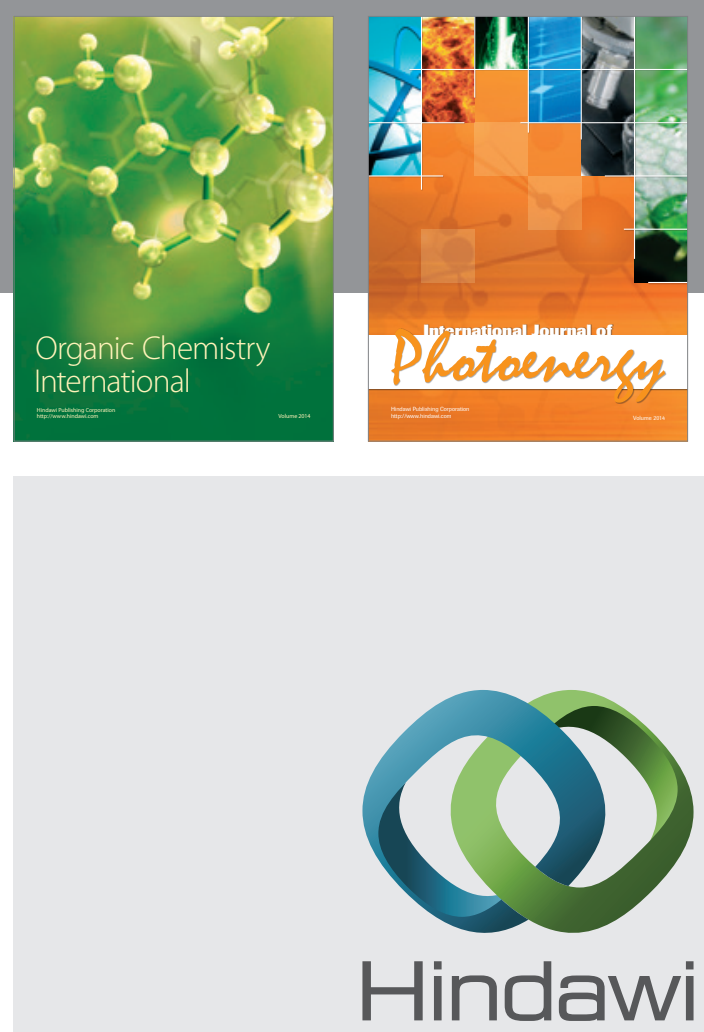

Submit your manuscripts at

http://www.hindawi.com

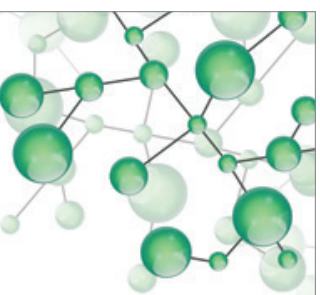

International Journal of

Inorganic Chemistry

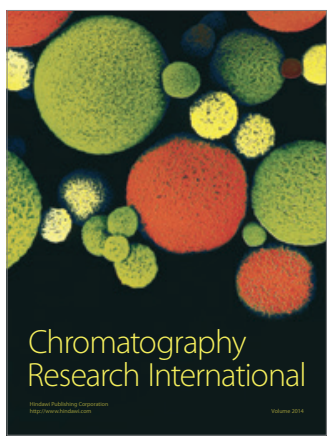

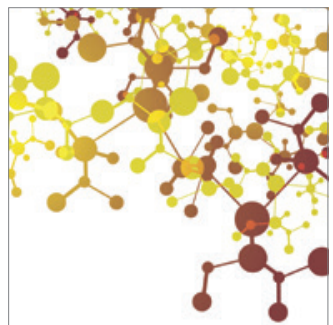

Applied Chemistry
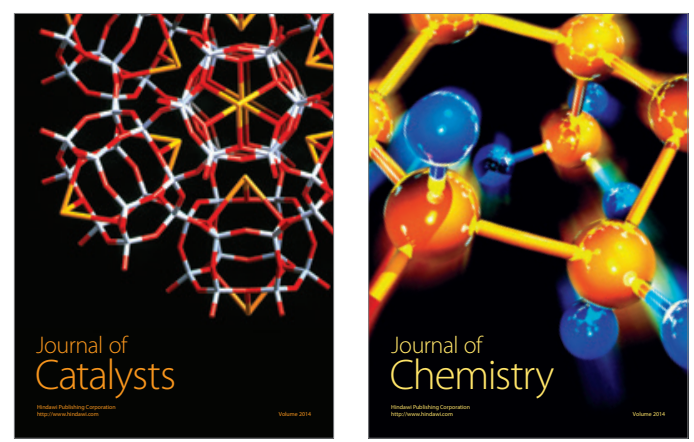
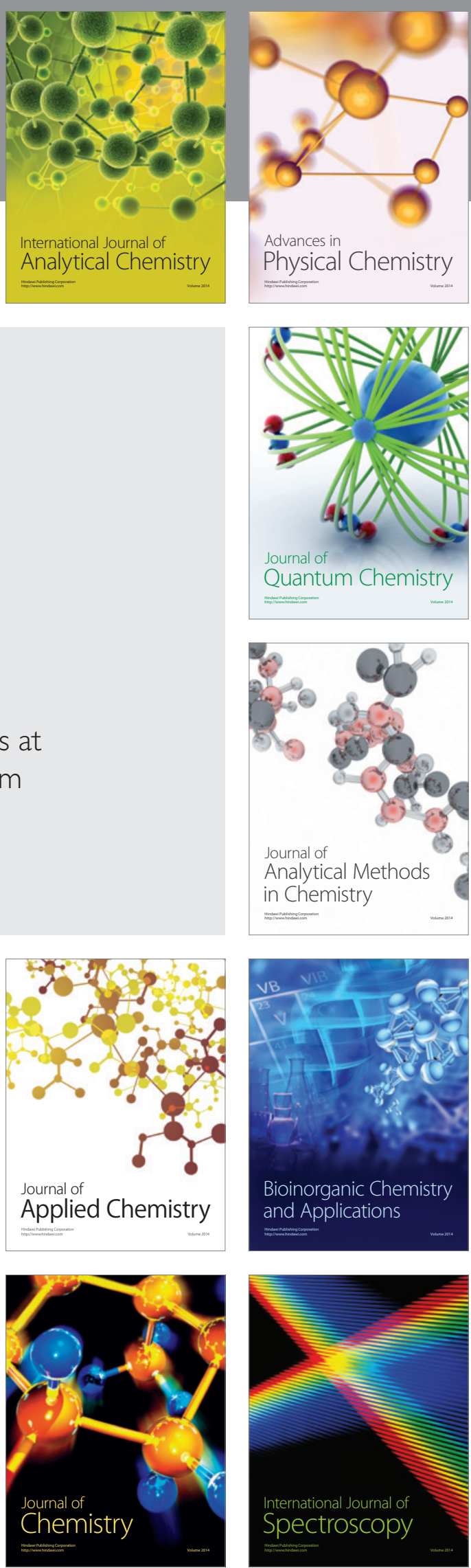